\title{
Efektivitas Pembelajaran Berorientasi Matematika Realistik untuk Membangun Pemahaman Relasional pada Materi Peluang
}

\author{
Fathur Rahmi ${ }^{1}$, Iltavia ${ }^{2}$, Ramzil Huda Zarista ${ }^{3}$ \\ ${ }^{1,2}$ Program Studi Pendidikan Matematika, Fakultas Ilmu Tarbiyah dan Keguruan, Institut Agama Islam Negeri Bukittinggi, \\ J1. Gurun Aua, Kubang Putiah, Bukittinggi, Indonesia \\ ${ }^{3}$ Program Studi Pendidikan Matematika, STKIP Sinar Cendekia,_Jl. Lengkong Gudang Timur Raya, Kec. Serpong, Kota \\ Tangerang Selatan, Banten, Indonesia \\ fathurrahmi@iainbukittinggi.ac.id
}

\begin{abstract}
Mathematics is one of the subjects that are cultivated from elementary, middle to higher education levels. One of the demands of learning mathematics is the ability of students in relational understanding. By mastering these abilities, students will get a way to move easily and skillfully. However, according to its development, there are still many students who have difficulty mastering the concepts of mathematics itself, especially on the material of opportunity. Therefore, researchers are interested in conducting research to see the ability of relational understanding on the material of opportunity. One of the efforts offered is by learning realistic mathematics. The research method used is one group pretest-posttest design. The population in this study was class VIII MTsM Sulit Air students in the semester II of the 2020-2021 Academic Year. The sample is class VIII 2 students in the same school year. The results of this study obtained an N-Gain value of 0.57 in the medium effect category. Based on the category of effectiveness interpretation, it is $56.81 \%$ in the criteria of being quite effective. The conclusion of this study is the effectiveness of realistic mathematics-oriented learning to build a relational understanding of the probability material.
\end{abstract}

Keywords: Realistic Mathematics Education, Relational Understanding, Probability

\begin{abstract}
Abstrak
Matematika termasuk salah satu mata pelajaran yang digeluti dari tingkat dasar, menengah hingga perguruan tinggi. Salah satu tuntutan dari pembelajaran matematika adalah kemampuan siswa dalam pemahaman relasional. Dengan dikuasainya kemampuan tersebut, siswa akan mendapatkan cara untuk bergerak dengan mudah dan terampil. Namun sesuai perkembangannya, kebanyakan siswa menghadapi kesulitan dalam menguasai konsep matematika, khususnya materi peluang. Oleh karena itu, peneliti tertarik melakukan penelitian untuk melihat kemampuan pemahaman relasional pada materi peluang. Salah satu upaya yang ditawarkan menggunakan pendekatan matematika realistik. One group pretest-posttest design menjadi pilihan metode penelitiannya. Populasinya adalah siswa kelas VIII MTsM Sulit Air semester II Tahun Ajaran 2020-2021. Sampelnya adalah siswa kelas $\mathrm{VIII}_{2}$ pada tahun pelajaran yang sama. Hasil dari penelitian ini didapatkan nilai N-Gain sebesar 0.57 dalam kategori efek sedang. Berdasarkan kategori tafsiran efektivitas adalah sebesar $56.81 \%$ dalam kriteria cukup efektif. Kesimpulannya adalah pembelajaran berorientasi matematika realistik efektif dalam membangun pemahaman relasional untuk materi peluang.
\end{abstract}

Kata kunci: Pendidikan Matematika Realistik, Pemahaman Relasional, Peluang

Copyright (c) 2021 Fathur Rahmi, Iltavia, Ramzil Huda Zarista

$\triangle$ Corresponding author: Fathur Rahmi

Email Address: fathurrahmi@iainbukittinggi.ac.id (Jl. Gurun Aua, Kubang Putiah, Bukittinggi)

Received 08 June 2021, Accepted 31 August 2021, Published 06 September 2021

\section{PENDAHULUAN}

Pendidik memegang peranan penting di dunia pendidikan. Sementara itu, pendidikan memegang penting dalam meningkatkan sumber daya manusia. Hal tersebut tentunya menuntut pendidik untuk meningkatkan kualitas pribadinya dalam berbagai bidang terutama dalam hal berpikir kreatif, memiliki wawasan luas dan juga mengikuti perkembangan zaman untuk memenuhi kebutuhan siswa.

Turmudi dalam bukunya menyatakan bahwa sudah sejak lama ahli pendidikan dan ahli pendidikan matematika mengupayakan agar matematika mampu dipahami siswa dengan baik. 
Matematika merupakan suatu mata pelajaran utama untuk semua kelas sehingga menuntut siswa untuk memahami materi dan konsep dengan baik dan benar (Zarista, Asmar, and Yerizon, 2020). Namun demikian, hasilnya masih menunjukkan bahwa dalam setiap kelas hanya sebagian kecil siswa menyukai matematika (Turmudi 2008). Sejalan dengan pendapat (Arifah, U., \& Saefudin, A. 2017) menyatakan bahwa siswa masih belum memahami konsep dari materi yang diajarkan termasuk salah satu penyebab siswa menganggap matematika itu sulit. Hal tersebut terjadi karena siswa hanya mampu mengerjakan soal-soal matematika berdasarkan contoh yang diberikan oleh pendidik, jika soal yang diberikan berbeda dengan yang dicontohkan maka siswa mengalami kesulitan mengerjakannya (Akbar, Hamid, 2018). Hal tersebut kemungkinan karena kekeliruan guru saat pelaksanaan pembelajaran yaitu guru tidak mengaitkannya dengan kehidupan nyata (Sutisna, A., P., Maulana, Subarjah, 2016). Siswa masih belum mampu menyelesaikan permasalahan tekait aktivitas keseharian dengan konsep matematika termasuk materi peluang.

Peluang merupakan materi di mata pelajaran matematika yang berguna dalam aktivitas kehidupan sehari-hari manusia. Peluang adalah cara yang digunakan dalam memprediksi kemungkinan terjadinya sebuah peristiwa. Mengingat banyak ketidakpastian kehidupan sehari-hari seperti kesehatan, cuaca, kelahiran, kematian dan permainan yang mengarah pada konsep kebetulan atau variabel acak sebagai hasil dari percobaan (misalnya, panjang objek, ketinggian orang, suhu di kota pada hari tertentu dan lain-lain.). Banyak hal yang kita lakukan dan kejadian yang terjadi disekitar kita terus menerus dan sepenuhnya hasil tersebut bisa diprediksi. Hal tersebut menandakan bahwa peluang sudah dikenal sejak lama dan sebenarnya merupakan aktivitas manusia yang secara langsung tidak disadari.

Sepanjang masa remaja, masalah probabilistik tetap menjadi tantangan serius dan hanya sebagian kecil sekolah menengah siswa mampu memecahkan masalah probabilistik dengan benar dan bereaksi secara memadai dalam situasi ketidakpastian (Heyvaert et al. 2018). Ternyata, berbagai kesalahpahaman tentang probabilitas secara serius menghambat penalaran probabilistik formal di sekolah menengah (Batanero and Sanchez 2005). Siswa mengalami kesulitan saat memahami pelajaran matematika khususnya pembelajaran peluang dalam bentuk soal cerita, siswa kurang tepat saat penggunaan rumus sehingga siswa mengalami kesalahan dalam pengerjaan soal dan siswa tidak paham soal pada level kognitif aplikasi (Putridayani, I., B \& Chotimah, 2020). Hal tersebut menambahkan asumsi bahwa terbiasa menghafal rumus adalah salah satu kesalahan dalam menanamkan solusi dari suatu permasalahan sehingga hal tersebut tidak mampu membantu dalam menumbuhkan pola pikir siswa dalam materi peluang. Padahal peluang berhubungan erat dengan aktivitas kehidupan manusia. Peluang merupakan suatu prakiraan besar kemungkinan akan suatu kejadian. Selain itu, kemampuan matematis yang seharusnya dimiliki siswa saat belajar matematika khususnya peluang adalah pemahaman relasional.

Pemahaman relasional sangat penting dalam matematika, karena siswa yang memiliki pemahaman relasional lebih banyak kemungkinan untuk mengenali hubungan fungsional dalam konsep dan dengan benar merepresentasikannya dari pada siswa yang memiliki pemahaman operasional 
(Blanton et al. 2018). Fenwick \& Edwards berpendapat bahwa pemikiran relasional memusatkan perhatian pada solusi yang menghubungkan materi satu dengan lainnya. Sebagai akibatnya, cara tertentu dalam melakukan sesuatu (sebuah praktik) yang muncul secara terus-menerus dalam penemuan solusi dan itu hanya bisa ditemukan dengan cara percobaan (Decuypere and Simons 2016). Pemahaman relasional bukan merupakan informasi yang harus 'disampaikan' kepada siswa satu kali, tetapi secara bertahap oleh prosedur penalaran dan inferensi bahwa siswa dapat menaklukkan interkoneksi logis antara konsep (Karakonstantis and Patronis 2010). Siswa saat mengembangkan pemahaman relasional, mereka memperoleh cara untuk bergerak dengan mudah dan terampil (Jaber and BouJaoude 2012). Oleh karena itu, pemahaman relasional akan menghasilkan pengetahuan konsep sehingga siswa mampu memahami langkah-langkah saat menyelesaikan masalah serta mampu menghubungkan suatu konsep dengan konsep materi lain.

Pemahaman relasional yang ada pada diri siswa butuh dibentuk dan dikembangkan oleh sekolah (Riyani, R., Maizora, S. 2017). Siswa harus memiliki pemahaman relasional yang bagus dalam pembelajaran peluang. Hal tersebut membuat siswa mampu menemukan konsep peluang dan mengingat materi peluang lebih lama nantinya karena matematika termasuk ilmu yang diajarkan kepada siswa mulai dari tingkat dasar sampai perguruan tinggi. Kenyataannya, pemahaman relasional siswa dalam pembelajaran peluang masih kurang sehingga menghambat siswa menyelesaikan permasalahan yang diberikan.

Kendala yang dihadapi siswa adalah proses belajarnya tidak kreatif, hal tersebut terbukti saat wawancara dengan pendidiknya. Pendidik tidak menggunakan alat dan media yang tepat dan hanya mengandalkan buku kurtilas sebagai media pembelajaran, pendidik juga mengatakan hanya memberikan rumus saat pembelajaran. Padahal kemampuan pemahaman relasional bisa ditingkatkan dengan pembelajaran yang inovatif dan kreatif. Noyes mengatakan banyak anak yang dilatih untuk melakukan perhitungan matematis alih-alih dididik berpikir matematis (Wijaya 2013). Harusnya pendidik lebih memperhatikan bagaimana membuat matematika bermakna bagi semua siswa, dibutuhkan membuatnya sesuai dengan perkembangan, bekerja dengan pertanyaan, memungkinkan untuk mendalam dan menawarkan kegiatan menantang (Hurt and Tomoyasu 1995). Beberapa hal seperti pemecahan masalah matematika yang inovatif seringkali membutuhkan pertanyaan dan penemuan, hasilnya dapat memicu minat untuk belajar tentang matematika. Gagasan dasarnya adalah membuat siswa melampaui siswa yang patuh, yang hanya menjawab pertanyaan yang diajukan pendidik. Mendukung hal tersebut, perlu sebuah pendekatan dalam pembelajaran yang mampu meningkatkan minat siswa sehingga siswa menyukai dan tidak merasa kesulitan untuk mempelajari matematika.

Pendidikan matematika realistik termasuk pendekatan menjanjikan dalam pembelajaran matematika (Hadi, 2017). Pendekatan pendidikan matematika realistik termasuk pendekatan yang menganggap bahwa matematika bukanlah sebuah produk jadi ilmu pengetahuan, bukan penghafalan rumus, bukan kegiatan mengingat konsep/ definisi suatu materi dengan menghafal saja tapi aktivitas yang dilakukan guna agar siswa mampu memahami konsep dengan baik sehingga mampu menjawab 
permasalahan yang berhubungan dengan materi yang dipelajarinya. Pendekatan ini mengajarkan sesuatu sesuai dengan konteks yang dekat dengan siswa, sehingga siswa juga paham apa manfaat peluang dalam kehidupan dan juga siswa mampu mengingat konsep dalam jangka waktu lama sebab berhubungan dengan aktivitas manusia.

Selain itu, pembelajaran matematika realistik membantu agar pembelajaran tidak membosankan. Hal tersebut tentu harus didukung dengan desain pembelajaran yang dibuat oleh pendidik. Hasil penelitian (Rahmi, Sampoerno, and Ambarwati 2020) yaitu berdasarkan wawancara yang telah dilakukan dengan siswa kemampuan rendah, mereka memahami konsep probabilitas yang diberikan sebagai proporsi dan siswa juga lebih bersemangat saat belajar menggunakan pendekatan pendidikan matematika realistik. Hal lain yang tidak terduga juga, selama proses pembelajaran peluang empirik kemampuan siswa yang berkemampuan rendah lebih bagus dari pada kemampuan siswa yang lebih tinggi. Berdasarkan hal tersebut, kami berminat untuk melaksanakan penelitian dengan judul "Efektivitas Pembelajaran Berorientasi Matematika Realistik untuk Membangun Pemahaman Relasional Pada Materi Peluang".

\section{METODE}

Populasi penelitian yaitu siswa kelas VIII MTsM Sulit Air semester II Tahun Ajaran 2020-2021. Sampelnya adalah siswa kelas $\mathrm{VIII}_{2}$ pada tahun pelajaran yang sama. Rancangan penelitian yang digunakan adalah one group pre-test post-test design, sedangkan instrumennya adalah tes hasil belajar pemahaman relasional siswa sebelum dan sesudah diberi perlakuan. Disaat proses pembelajaran, peneliti menerapkan pendekatan pendidikan matematika realistik. Setelah itu, peneliti memberikan tes akhir untuk melihat kemampuan siswa.

Variabel penelitiannya adalah hasil belajar pemahaman relasional (pretest) sebelum diberikan perlakuan dan hasil belajar pemahaman relasional (posttest) setelah diberikan perlakuan menggunakan pendekatan matematika realistik model pembelajaran kooperatif tipe scramble. Pengelompokan data yang digunakan yaitu data primer dan data sekunder. Data primer yang digunakan adalah hasil belajar pemahaman relasional matematika siswa. Data sekunder yang digunakan adalah siswa kelas VIII MTsM Sulit Air semester II Tahun Ajaran 2020-2021.

Instrumen yang digunakan adalah tes hasil belajar pemahaman relasional dalam bentuk essay. Data hasil belajar pemahaman relasional diperoleh melalui tes akhir. Pengumpulan data dilakukan dengan memberikan pretest dan posttest pada kelas eksperimen dengan terdapat efektivitas perlakuan yang diberikan.

Analisis data digunakan untuk menguji hipotesis penelitian, yakni untuk melihat apakah terdapat efektivitas perlakuan yang diberikan terhadap peningkatan hasil belajar pemahaman relasional matematika siswa. Uji hipotesis menggunakan Gain Ternormalisasi (N-Gain) yang merupakan perbandingan skor gain actual dengan skor gain maksimal. Peningkatan ini diambil dari nilai pretest dan posttest siswa. Rumus untuk menghitung skor gain ternormalisasi adalah: (Hurt and Tomoyasu 1995) 


$$
\mathrm{N} \text { Gain }=\frac{\text { skor } \text { Posttest }- \text { skor pretest }}{\text { skor ideal-skor pretest }}
$$

Adapun kriteria effect size dapat dilihat pada tabel berikut:

Tabel 1. Kriteria Effect Size

\begin{tabular}{|l|l|}
\hline \multicolumn{1}{|c|}{ Ukuran efek } & \multicolumn{1}{c|}{ Kriteria } \\
\hline $0<\mathrm{g}<0,2$ & Efek kecil \\
\hline $0,2<\mathrm{g}<0,8$ & Efek sedang \\
\hline $\mathrm{d}>0,8$ & Efek besar \\
\hline
\end{tabular}

Untuk melihat persentase efektifitas pembelajaran matematika realistik, penelitian ini menggunakan kategori tafsiran efektivitas N-Gain dengan kategori sebagai berikut:

Tabel 2. Kategori tafsiran efektifitas N-Gain

\begin{tabular}{|c|c|}
\hline Persentase (\%) & Kriteria \\
\hline$<40$ & Tidak efektif \\
\hline $40-55$ & Kurang efektif \\
\hline $56-75$ & Cukup efektif \\
\hline$>76$ & Efektif \\
\hline
\end{tabular}

\section{HASIL DAN DISKUSI}

\section{Hasil}

Pada bagian ini dideskripsikan data tentang hasil belajar pemahaman relasional siswa yang dilihat melalui tes tertulis di kelas VIII. Hasil belajar pemahaman relasional siswa diperoleh melalui tes. Tes dilakukan dua kali yaitu sebelum dan sesudah pembelajaran. Pretest dan posttest yaitu terdiri dari uraian sebanyak 7 butir dan dikerjakan dalam waktu 80 menit. Pretest dan posttest pada kelas penelitian diikuti oleh 20 siswa masing-masingnya.

Terdapat perbedaan rata-rata hasil belajar kognitif pada nilai pretest dan posttest, yaitu hasil pretest lebih rendah dari posttest baik dilihat dari nilai tertinggi maupun nilai terendah. Untuk data hasil belajar siswa bisa dilihat pada tabel berikut:

Tabel 3. Data Hasil Belajar Pemahaman Relasional Siswa

\begin{tabular}{|l|l|l|l|l|}
\hline Jenis & Jumlah & Nilai Rata- & \multicolumn{2}{|c|}{ Persentase } \\
\cline { 4 - 5 } & Siswa & Rata & Tuntas & Tidak Tuntas \\
\hline Pretest & 20 & 54,1 & $15 \%$ & $85 \%$ \\
\hline Posttest & 20 & 79,5 & $75 \%$ & $25 \%$ \\
\hline
\end{tabular}

Rata-rata nilai siswa pada saat posttest 79,5, sedangkan pretest 54,1. Selain itu, bisa diperhatikan persentase peningkatan ketuntasan siswa yang saat pretest hanya $15 \%$ menjadi $75 \%$ saat posttest. Berdasarkan analisis pada tabel diatas nilai n-gain yang didapat adalah sebesar 0,57 dalam kategori efek sedang. Berdasarkan kategori tafsiran efektivitas adalah sebesar 56,81\% dalam kriteria cukup efektif.

\section{Diskusi}

Tahap awal pada penelitian ini, pretest diberikan kepada siswa kelas $\mathrm{VIII}_{2}$ untuk mengetahui kemampuan awal kelas sampel. Keberhasilan pembelajaran matematika realistik diukur melalui 
posttest.

Tabel 4. Analisis Hasil Belajar Pemahaman Relasional Siswa

\begin{tabular}{|c|c|c|c|c|c|c|c|}
\hline \multirow{2}{*}{ No } & \multirow{2}{*}{$\begin{array}{l}\text { Kode } \\
\text { Siswa }\end{array}$} & \multicolumn{2}{|c|}{ Nilai } & \multirow{2}{*}{$\begin{array}{l}\text { Post- } \\
\text { Pre }\end{array}$} & \multirow{2}{*}{$\begin{array}{c}\text { Skor Ideal } \\
\text { 100-Pre }\end{array}$} & \multirow{2}{*}{$\begin{array}{c}\text { N-Gain } \\
\text { Score }\end{array}$} & \multirow{2}{*}{$\begin{array}{c}\text { N-Gain } \\
\text { Score Persen }\end{array}$} \\
\hline & & Pre & Post & & & & \\
\hline 1 & A1 & 45 & 70 & 25 & 55 & 0,45 & 45,45 \\
\hline 2 & $\mathrm{~A} 2$ & 70 & 88 & 18 & 30 & 0,60 & 60,00 \\
\hline 3 & A3 & 78 & 89 & 11 & 22 & 0,50 & 50,00 \\
\hline 4 & A4 & 35 & 67 & 32 & 65 & 0,49 & 49,23 \\
\hline 5 & A5 & 79 & 97 & 18 & 21 & 0,86 & 85,71 \\
\hline 6 & A6 & 34 & 67 & 33 & 66 & 0,50 & 50,00 \\
\hline 7 & A7 & 55 & 77 & 22 & 45 & 0,49 & 48,89 \\
\hline 8 & $\mathrm{~A} 8$ & 50 & 87 & 37 & 50 & 0,74 & 74,00 \\
\hline 9 & A9 & 34 & 56 & 22 & 66 & 0,33 & 33,33 \\
\hline 10 & A10 & 45 & 50 & 5 & 55 & 0,09 & 9,09 \\
\hline 11 & A11 & 55 & 88 & 33 & 45 & 0,73 & 73,33 \\
\hline 12 & A12 & 88 & 95 & 7 & 12 & 0,58 & 58,33 \\
\hline 13 & A13 & 58 & 76 & 18 & 42 & 0,43 & 42,86 \\
\hline 14 & A14 & 46 & 78 & 32 & 54 & 0,59 & 59,26 \\
\hline 15 & A15 & 47 & 78 & 31 & 53 & 0,58 & 58,49 \\
\hline 16 & A16 & 38 & 89 & 51 & 62 & 0,82 & 82,26 \\
\hline 17 & A17 & 59 & 80 & 21 & 41 & 0,51 & 51,22 \\
\hline 18 & A18 & 59 & 89 & 30 & 41 & 0,73 & 73,17 \\
\hline 19 & A19 & 50 & 89 & 39 & 50 & 0,78 & 78,00 \\
\hline 20 & A20 & 57 & 80 & 23 & 43 & 0,53 & 53,49 \\
\hline & & 54,1 & 79,5 & & & 0,57 & 56,81 \\
\hline
\end{tabular}

Dari kedua nilai yang didapat, dilakukan uji gain untuk hasil belajar pemahaman relasional pretest dan posttest. Setelah dilakukan perhitungan diperoleh nilai N-Gain sebesar 0,57 dalam kategori efek sedang. Berdasarkan kategori tafsiran efektivitas adalah sebesar 56,81\% dalam kriteria cukup efektif. Pembahasan dan hasil penelitian tersebut didukung oleh beberapa penelitian lainnya yang mendukung pendekatan pendidikan realistik matematika mampu meningkatkan kemampuan hasil belajar siswa, khususnya kemampuan relasional. Penelitian (Iltavia 2010) menyebutkan Lembar Kerja Siswa (LKS) berbasis pendekatan Realistics Mathematics Education (RME) yang sudah valid, praktis dan efektif mampu meningkatkan hasil belajar siswa menjadi lebih dari $70 \%$ mencapai KKM. Penelitian selanjutnya (Wulandari, Darma, and Susiaty 2019) terlihat bahwa dengan menggunakan pendekatan matematika realistik siswa mampu memahami materi yang diberikan. Penelitian Rahmi, Sampoerno and Ambarwati (2021) juga menyimpulkan bahwa siswa mampu mengingat konsep peluang dan memahami soal tanpa harus mengingat rumus dengan menggunakan pendekatan pendidikan matematika realistik. Selain itu (Olivia, Meiliasari, and Deniyanti 2013) menyatakan bahwa hasil analisis retrospektif, konteks yang digunakan pada tiap pertemuan dapat mengembangkan pemahaman siswa. Diskusi kelompok dan diskusi kelas juga memberi kontribusi dalam pengembangan pemahaman relasional siswa. Sedangkan 
penelitian yang dilakukan oleh (Hanifah, Noornia, and Sampoerno 2019) menunjukan bahwa secara keseluruhan penggunaan konteks yang tepat sesuai materi serta peran aktif siswa dan guru dalam pembelajaran sesuai dengan karakteristik pendidikan matematika realistik dapat menumbuhkan dan membangun pemahaman relasional siswa. Dari beberapa penelitian yang sudah dijabarkan, hal ini menunjukan bahwa pendekatan tersebut mampu meningkatkan hasil belajar matematika siswa dari berbagai aspek bidang matematika, khususnya kemampuan pemahaman relasional pada materi peluang.

Berdasarkan pembahasan di atas, disimpulkan bahwa pembelajaran menggunakan pendekatan pendidikan matematika realistik efektif pada hasil belajar pemahaman relasional siswa materi peluang di kelas VIII. Jadi, dapat dideskripsikan beberapa hal sebagai berikut:

1. Penggunaan konteks masalah realistik dalam penelitian ini bermanfaat dengan baik. Konteks yang digunakan untuk setiap pertemuan sama yaitu penjualan pulsa. Hal tersebut menarik perhatian siswa dalam proses memahami kembali konsep perbandingan dan himpunan dan dalam memahami materi peluang.

2. Berdasarkan konteks masalah yang diberikan, siswa menggunakan model selama penelitian ini dengan menggunakan pernyataan untuk menjembatani pengetahuan siswa dari tingkat konkret ke tingkat yang lebih formal. Penggunaan konteks pada setiap pertemuan mampu membantu siswa mengembangkan kemampuan pemodelan dalam pembelajaran matematika.

3. Hasil konstruksi siswa sangat berperan dalam pembelajaran karena siswa mampu menggunakan pengetahuan yang dimilikinya untuk membangun pengertian terhadap suatu konsep dan mampu digunakan dalam memberikan solusi terhadap masalah yang diberikan.

4. Berdasarkan pembelajaran juga tergambar, mulai dari siswa menyelesaikan permasalahan yang diberikan sampai dengan diskusi dan presentasi.

5. Interaktivitas antara guru dan siswa maupun siswa dengan siswa lainnya berjalan baik dalam diskusi kelompok maupun saat presentasi. Guru memiliki peran sebagai fasilitator dalam memotivasi dan mengarahkan siswa saat mencari solusi permasalahan.

\section{KESIMPULAN}

Berdasarkan hasil penelitian, nilai N-Gain sebesar 0.57 dalam kategori efek sedang dengan kategori tafsiran efektivitas adalah sebesar $56.81 \%$ dalam kriteria cukup efektif. Jadi, disimpulkan bahwa hasil belajar pemahaman relasional matematika siswa dengan menggunakan pembelajaran matematika realistik efektif meningkatkan hasil belajar pemahaman relasional matematika siswa kelas VIII.

\section{UCAPAN TERIMA KASIH}

Ucapan terima kasih kepada Kepala LPPM IAIN Bukittinggi, Ketua Program Studi Pendidikan Matematika FTIK IAIN Bukittinggi. Terima kasih atas dukungan dan kerjasamanya sehingga penelitian ini berjalan dengan lancar. Terima kasih kepada kepala sekolah dan guru MTsM Sulit Air yang telah mengizinkan untuk melakukan penelitian serta orang tua dan sahabat yang telah mendukung serta 
memberi semangat.

\section{REFERENSI}

Akbar, Hamid, Bernard \&. Sugandi. 2018. “Analisis Kemampuan Pemecahan Masalah Dan Disposisi Matematik Siswa Kelas Xi Sma Putra Juang Dalam Materi Peluang." Journal Cendekia: Jurnal Pendidikan Matematika 2((1)):144-53.

Arifah, U., \& Saefudin, A., A. 2017. "Menumbuhkambangkan Kemampuan Pemahaman Konsep Matematika Dengan Menggunakan Model Pembelajaran Guided Discovery." UNION: Jurnal Pendidikan Matematik 5((3)):263-72.

Batanero, Carmen, and Ernesto Sanchez. 2005. "What Is the Nature of High School Students' Conceptions and Misconceptions About Probability?" Exploring Probability in School (January):241-66. doi: 10.1007/0-387-24530-8_11.

Blanton, Maria, Yenny Otálora, Bárbara M. Brizuela, Angela Murphy Gardiner, Katharine B. Sawrey, Aliska Gibbins, and Yangsook Kim. 2018. "Exploring Kindergarten Students' Early Understandings of the Equal Sign.” Mathematical Thinking and Learning 20(3):167-201. doi: 10.1080/10986065.2018.1474534.

Decuypere, Mathias, and Maarten Simons. 2016. "Relational Thinking in Education: Topology, Sociomaterial Studies, and Figures." Pedagogy, Culture and Society 24(3):371-86. doi: $10.1080 / 14681366.2016 .1166150$.

Hadi, Sutarto. 2017. "Pendidikan Matematika Realistik Teori,Pengembangan Dan Implementasinya." Jakarta : PT Raja Grafindo Persada 15(7):1967-75.

Hanifah, Rajibah, Anton Noornia, and Pinta Deniyanti Sampoerno. 2019. "Pengembangan Pembelajaran Dalam Membangun Pemahaman Relasional Siswa Melalui Pendekatan Pmri Materi Relasi Fungsi.” Prima: Jurnal Pendidikan Matematika 3(2):103. doi: 10.31000/prima.v3i2.950.

Heyvaert, Mieke, Maarten Deleye, Lore Saenen, Wim Van Dooren, and Patrick Onghena. 2018. "How Do High School Students Solve Probability Problems? A Mixed Methods Study on Probabilistic Reasoning." International Journal of Research \& Method in Education 41(2):184-206. doi: 10.1080/1743727X.2017.1279138.

Hurt, Stephen, and Naomi Tomoyasu. 1995. Psychological Testing and Assessment.

Iltavia. 2010. "Efektivitas Lembar Kerja Siswa (Lks) Berbasis Pendekatan Realistics Mathematics Education (Rme).” XI(77):155-61.

Jaber, Lama Ziad, and Saouma BouJaoude. 2012. "A Macro-Micro-Symbolic Teaching to Promote Relational Understanding of Chemical Reactions." International Journal of Science Education 34(7):973-98. doi: 10.1080/09500693.2011.569959. 
Karakonstantis, J., and T. Patronis. 2010. "Relational Understanding and Paths of Reasoning through a Boolean Lattice Classification of Quadrilaterals." International Journal of Mathematical Education in Science and Technology 41(3):341-49. doi: 10.1080/00207390903477434.

Olivia, P. Meiliasari, and C. Deniyanti. 2013. "Mengembangkan Pemahaman Relasional Siswa Mengenai Luas Bangun Datar Segiempat Dengan Pendekatan PMRI.” (November):125-32.

Putridayani, I., B \& Chotimah, S. 2020. “Analisis Kesulitan Belajar Siswa Dalam Pelajaran Matematika Pada Materi Peluang." MAJU 7((1)):57-62.

Rahmi, F., P. D. Sampoerno, and L. Ambarwati. 2020. "Probability Learning Trajectory: Students' Emerging Relational Understanding of Probability through Ratio." Journal of Physics: Conference Series 1470(1). doi: 10.1088/1742-6596/1470/1/012067.

Rahmi, F., P. D. Sampoerno, and L. Ambarwati. 2021. "Building Relational Understanding Through Hypothetical Learning Trajectory of Probability." International Journal of Elementary Education 5(1):150-157.

Riyani, R., Maizora, S., \&. Hanifah. 2017. “Uji Validitas Pengembangan Tes Untuk Mengukur Kemampuan Pemahaman Relasional Pada Materi Persamaan Kuadrat Siswa Kelas VIII SMP.” Jurnal Penelitian Pembelajaran Matematika Sekolah (JP2MS) 1((1)):60-65.

Sutisna, A., P., Maulana, Subarjah, H. 2016. "Meningkatkan Pemahaman Matematis Melalui Pendekatan Tematik Dengan RME.” Jurnal Pena Ilmiah 1((1)):31-40.

Turmudi. 2008. "Pembelajaran Matematika Exploratif Dan Investigatif Berwawasan Inovatif." (1):110.

Wijaya, Ariyadi. 2013. Pendidikan Matematika Realistik; Suatu Alternatif Pendekatan Pembelajaran Matematika.

Wulandari, Syafitri, Yudi Darma, and Utin Desy Susiaty. 2019. "Pengembangan Modul Berbasis Pendekatan Realistic Mathematics Education (Rme) Terhadap Pemahaman Konsep.” Jurnal Pendidikan Informatika Dan Sains 8(1):143. doi: 10.31571/saintek.v8i1.1179.

Zarista, R. H., A. Asmar, and Y. Yerizon. 2020. "The Validity of Mathematic Learning Device Based on Learning Cycle to Improve Reasoning Abilities of Junior High School's Students." in Journal of Physics: Conference Series. Vol. 1554. 